
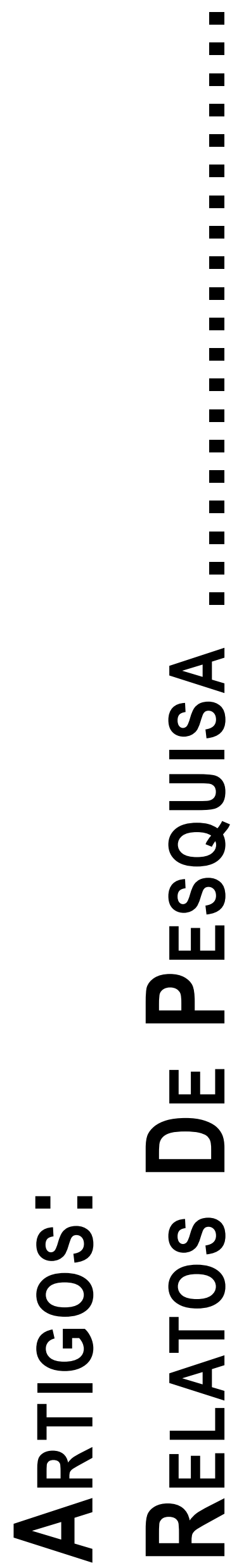


\title{
GRUPO INTERVENTIVO COM GENITORES (AS) DE CRIANÇAS VÍTIMAS DE VIOLÊNCIA SEXUAL
}

\author{
Intervention Group with Parentes of Children Victims of Sexual Violence
}

Grupo Interventivo con Padres y Madres de Niños Víctimas de Violencia Sexual

GLEDSON WILBER DE SOUZA SHIRLEY MACÊDO

\begin{abstract}
Resumo: Esta pesquisa fenomenológica-interventiva teve como objetivo principal compreender o sentido da experiência de ser genitor (a) de criança vítima de violência sexual, buscando possibilitar a ressignificação da realidade e a elaboração de estratégias de enfrentamento. Em três encontros semanais de uma hora e meia, cinco genitores e o próprio pesquisador registraram o sentido de suas experiências dos encontros em Versão de Sentido (VS). De posse de todas as VS's, foi possível compreender que o sofrimento presente na vida dos colaboradores está relacionado com a lentidão entre denúncia do abuso e conclusão de trâmites jurídicos. O processo levou os colaboradores a mudanças em modos de subjetivação, principalmente, devido à ampliação da visão sobre si mesmos, o que resultou em ressignificação da própria história de vida e na construção de projetos futuros. Além da oportunidade de minimizar seu sofrimento pelo compartilhamento deste com outros, eles criaram como estratégia de enfrentamento da realidade: a construção de vínculos sociais para partilhar suas experiências, falar sobre o próprio sofrimento e cuidar de si. Concluiu-se, principalmente, que a prática dos encontros foi absorvida pelos colaboradores como estratégia de autocuidado, e o acolhimento ofertado deve focá-los para além da condição de genitores de vítimas de violência sexual.
\end{abstract}

Palavras-chave: Violência Sexual Infantil; Família; Pesquisa Fenomenológica

\begin{abstract}
This phenomenological-intervention research had as its main objective understanding the experience of being a parent of a child victim of sexual violence, seeking to re-signify reality and the elaboration of coping strategies. In three one-and-a-half-hour weekly meetings, five parents and the researcher themselves recorded the meaning of their experiences and encounters in Sense Version (SV). With the possession of all SVs, it was possible that the present suffering in the employees' lives is related to a slowness between denouncing the abuse and completing legal procedures. The process led the employees to change in modes of subjectivation, mainly due to the enlargement of the vision about themselves, which resulted in a re-signification of their own life history and the construction of future projects. In addition to the opportunity to minimize their suffering by sharing it with others, they have created strategies of coping with reality: to build social bonds to share their experiences, talk about their own suffering and take care of themselves. It was mainly concluded that the practice of the meetings was absorbed by the collaborators as a strategy of self-care, and the embracement offered must focus on them beyond the condition of parents of victims of sexual violence.
\end{abstract}

Keywords: Child Sexual Violence; Family; Phenomenological Research

Resumen: Esta investigación fenomenologico-interventiva tuvo como principal objetivo comprender el sentido de las experiencias de padres de niños víctimas de abuso sexual, buscando redefinir la realidad elaborando estrategias para afrontar la misma. En tres encuentros semanales de una hora y media, cinco padres y el investigador registraron el sentido de sus experiencias en VS., con éstas fue posible comprender que el sufrimiento de los familiares se puntualiza en la burogracia jurídica. En los colaboradores este proceso generó cambios en modos de subjetivación, principalmente en la ampliación de su visión sobre sí mismo. Esto concluye con la redefinición de sus vidas y la construcción de futuros proyectos. Al Compartir con otros sus experiencuas tienen la posibilidad de minimizar el sufrimiento, por lo que generaron vínculos sociales. Como conclusión principal, las actividades fueron aprovechadas por padres como estrategias de auto-cuidado, y la recepción debe enfocarse en padres de víctimas de abuso sexual

Palabras clave: Violencia Sexual Infantil; Familia; Investigación Fenomenológica

\section{Introdução}

No Brasil, as situações de maus-tratos infantis ganharam visibilidade no final da década de 1980. Foi nesse momento que a Constituição Federal, de 1988, e o Estatuto da Criança e do Adolescente (ECA), de 1990, passaram a exigir a notificação de casos suspeitos ou confirmados de violência infantil. A partir disso, então, as políticas de proteção à criança e ao adolescente começam a se firmar. Um dado importante é que, apesar de manter os altos índices de violência sexual infantil, o Brasil é tido, no âmbito internacional, como um dos países que mais luta contra essa problemática, graças à criação de uma legislação de caráter protetivo (Lima \& Alberto, 2010).

A violência sexual infantil pode se apresentar através do abuso ou exploração sexual. $\mathrm{O}$ abuso pode se configurar como todo jogo ou ato sexual seja ele hétero ou homossexual, entre um ou mais adultos com uma criança ou adolescente, tendo o objetivo de estimular sexualmente a 
criança ou adolescente, ou para obter satisfação sexual do próprio abusador, podendo ser utilizado o uso de força, ameaça ou indução da vontade da vítima (Azevedo, 1997). A exploração sexual é uma forma de violência sexual baseada numa lógica de mercantilização e uso de poder, buscando obter vantagem ou proveito lucrativo a partir do uso do corpo da criança ou do adolescente, seja pela ação criminosa individual ou a partir de uma rede de abuso (Leal, citado por Conselho Federal de Psicologia, 2009).

Esses tipos de violência podem ocorrer em dois contextos: no âmbito familiar, onde o agressor se encontra em um lugar de confiança, cuidado e poder em relação à criança; e no âmbito extrafamiliar, quando o agressor não faz parte diretamente das relações familiares, como, por exemplo, vizinhos ou desconhecidos (Habigzang, Ramos \& Koller, 2011).

Apesar de distintos, esses conceitos revelam a realidade de violação de direito vivenciada por inúmeras crianças e adolescentes. Entretanto, apesar de hoje ser um assunto tratado nas academias de ensino superior, nas produções científicas e nos meios de comunicação, nem sempre houve uma preocupação quanto à proteção e cuidado de crianças e adolescentes.

Mesmo existindo essa militância ativa, por algumas razões, muitos dos casos de violência sexual contra crianças no Brasil não são contabilizados nas estatísticas produzidas. Dentre esses motivos, é possível elencar como os mais significativos: a dificuldade de diagnóstico, o desconhecimento sobre a problemática e o receio de fazer a denúncia, pelo motivo de, na maioria dos casos, o agressor fazer parte do núcleo familiar (Zambon, Jacintho, Medeiros, Guglielminetti \& Marmo, 2012). Apesar dessa dificuldade, através dos registros do Sistema de Informação de Agravo de Notificação (SINAN), no Brasil, foram atendidas em 2011, um total de 10.425 crianças e adolescentes vítimas de violência sexual, sendo a maioria do sexo feminino: $83,2 \%$, com poucas oscilações entre as faixas etárias (Waiselfisz, 2012).

De 2011 até os dias atuais, a realidade não mudou. Segundo a Secretaria Especial de Direitos Humanos, no primeiro trimestre de 2015 o Disque 100 recebeu, somente no Nordeste brasileiro, 1.191 denúncias de casos de violência sexual contra crianças e adolescentes. Mais especificamente, na cidade de Petrolina, em Pernambuco, segundo os dados que constam nos registros do Centro de Referência Especializada em Assistência Social (CREAS) Municipal, no ano de 2015 foram acompanhados, no total, 31 casos de violência sexual infanto-juvenil. Já no ano de 2016, de janeiro a junho, foram atendidos 31 novos casos, ou seja, apenas no primeiro semestre de 2016 já se alcançou o número total de 2015. Os indicadores mostram, portanto, a necessidade de se pensar formas de enfrentamento da situação.

Para além de números, autores como Zambon et al. (2012) defendem que as experiências de violência sexual ocorridas durante a infância podem interferir de modo significativo no desenvolvimento de uma criança. Acreditam que os danos vão desde comportamentos não adaptativos e déficits emocionais, até transtornos mentais graves, como: comportamento impulsivo, transtorno de hiperatividade, problemas de aprendizado escolar, assim como transtornos da conduta e abuso de substâncias psicoativas na adolescência. Essas consequências não atingem somente a criança ou o adolescente, mas também a família, que, ao mesmo tempo em que vivencia o processo de sofrimento, precisa se estruturar para oferecer cuidado e proteção à vítima.

Frente a tais perspectivas teóricas e partindo de uma concepção diferente que não busca estabelecer relações causais, mas sim compreender a singularidade de experiências humanas, a participação como estagiário do CREAS Municipal de Petrolina nos atendimentos feitos a esse tipo de demanda permitiu que se constatasse o quanto a escuta e a intervenção psicológica são importantes no processo de ressignificação de uma realidade para pessoas que vivenciam sofrimento, no caso, genitores (as) que passaram pela experiência de terem filhos que sofreram violência sexual. Dessa forma, percebeu-se que o trabalho de acolhimento e cuidado continuado deveria ser destinado não apenas à criança violentada, mas também ao (à) genitor (a), que, indiretamente, também é agredido(a). E é a partir disso que essa pesquisa se propôs a compreender a realidade desses sujeitos e interferir na ressignificação do possível sofrimento vivenciado pela agressão.

Assim, parece necessário pensar sobre a importância da família em todo o processo que envolve esse tipo de violência, desde a sua descoberta até o momento de superação dos danos. Segundo Lima e Alberto (2010), “o apoio familiar torna-se fator imprescindível para o encaminhamento da situação de violência vivida pela criança e pelo adolescente” (p.130). Dessa forma, é muito relevante que os serviços da rede de combate à violência pensem em formas de atender essas famílias, melhor preparando-as para lidar com os traumas gerados pela agressão levando em conta que genitores (as) ou entes próximos também são violentados.

É um acontecimento que muda a estrutura familiar e atinge todos os envolvidos naquele ciclo, como bem enfatiza Paula (2011):

Esta ruptura se dá a partir do momento em que há a ocorrência de um evento não programado, de caráter traumático como a agressão sexual, que promove o rompimento da família com os seus projetos de continuidade de uma perspectiva, previamente elaborada e esperada, sobre o cotidiano (p.27).

Em certa medida, os familiares acabam vivenciando a violência de forma ampliada, principalmente no que diz respeito ao julgamento social e à autocobrança por terem falhado no papel 
de protetores. Isto porque o medo de ser julgado, na maioria das vezes, é maior que a expectativa de apoio através de sua rede social (Paula, 2011). É por esse motivo que as famílias acabam assumindo uma postura de afastamento do convívio com a comunidade, como afirma Costa, Penso, Rufini, Mendes e Borba (2007, p.251): "o silêncio contínuo e auto-imposto pode levar ao sentimento de humilhação social e consequente isolamento individual e familiar". Portanto, compreende-se o quanto esses indivíduos precisam de uma atenção direcionada, em espaços de acolhimento integral, nos quais, para além de receber orientações sobre que passos seguir no cuidado das crianças, possam sentir-se acolhidos e cuidados, possibilitando seu fortalecimento não apenas como genitores (as), mas também como atores e atrizes sociais.

São muitos os fatores que influenciam na fragilização dos genitores (as). Sanderson (2005, citado por Costa, et al. 2007), por exemplo, fala sobre o sentimento de traição vivenciado: primeiro eles se sentem traídos pelo abusador da criança (por geralmente o agressor ser alguém de confiança) e, ao mesmo tempo, sentem-se traidores, por não terem protegido o suficiente. Uma dualidade de sofrimento que acaba se intensificando, entre outros motivos, devido à convivência diária com a criança ou o adolescente, que faz recordar cotidianamente o sentimento de culpa. Sem contar com a quantidade de vezes que tanto genitores (as) como as vítimas são obrigados a relatar o fato nos órgãos da rede de apoio. É comum ouvir as queixas sobre a repetição da história do abuso e o desgaste causado por ela (Costa et al.,2007).

Por todo esse desgaste, o isolamento social parece ser uma alternativa de enfrentamento que os pais utilizam diante da problemática. Paula (2011) comenta que:

O acontecimento do abuso sexual dificilmente chega a ser comentado no ambiente de trabalho ou vizinhança, ou mesmo, em muitos casos, no ambiente religioso do qual fazem parte; (...) $\mathrm{O}$ abuso sexual contra crianças e adolescentes desperta na sociedade uma dura cobrança sobre os pais da criança, (...) Esse tipo de violência é encarado socialmente como algo imperdoável que deveria ser evitado pela família, principalmente se a violência foi cometida por um parente (p. 28).

Partindo dessa contextualização, são indagações desta pesquisa saber quais os sentidos da experiência de ser genitor (a) de criança ou adolescente vítima de violência sexual. Como se daria um processo interventivo de compartilhamento de experiências entre esses (as) genitores (as)? É possível que haja mudança nos modos de subjetivação desses sujeitos ao longo de um processo interventivo? Se sim, que mudanças seriam essas e que estratégias de enfrentamento da realidade poderiam ser construídas?

\section{Objetivos}

Nessa pesquisa, que se propôs a montar um grupo interventivo para genitores (as) que enfrentam a problemática em questão, teve-se como objetivo geral compreender o sentido da experiência de ser genitor (a) de criança vítima de violência sexual, buscando intervir na ressignificação da realidade e na elaboração de estratégias de enfrentamento. Como objetivos específicos, buscou-se: descrever o sentido da experiência de ser genitor (a) de criança ou adolescente vítima de violência sexual; descrever o processo vivido por esses sujeitos durante a pesquisa; identificar as mudanças nos modos de subjetivação desses sujeitos durante o próprio processo de pesquisa; e elencar as estratégias de enfrentamento construídas ao longo do processo.

\section{Método}

A presente pesquisa tratou-se de um estudo qualitativo interventivo de inspiração humanistafenomenológica, que produziu conhecimentos a partir da criação de encontros intersubjetivos de produção de sentido, focado em significados que os sujeitos atribuíram às suas experiências ao compartilhá-las num contexto de diálogo.

Para melhor compreensão do que seja a abordagem fenomenológica em pesquisa, parte-se das ideias de Capalbo (1994, citado por Garnica, 1997), que a define como método descritivo que se ocupa do vivido, e de Amatuzzi (2008), que assevera que uma pesquisa fenomenológica é focada no sentido da experiência humana.

Dentre as diversas perspectivas em pesquisas fenomenológicas, elegeu-se aquela que mescla pressupostos filosóficos de Merleau-Ponty e Gadamer: a hermenêutica-colaborativa (Macêdo, 2015). Merleau-Ponty vê na fenomenologia a oportunidade de ilustrar as relações vividas entre o homem e o mundo, valorizando o encontro entre o meu eu e o mundo e entre o meu eu e as coisas, sendo possível essa relação por intermédio do corpo (Spíndola, 1997). Para uma melhor compreensão da proposta de pesquisa aqui trabalhada, se faz necessário o esclarecimento de dois conceitos merleau-pontyanos: a epokhē incompleta e a intercorporeidade. Sobre a epokhē, MerleauPonty vem contrapor o pensamento de Husserl criticando o que este defende em relação à redução completa de si para compreender a experiência do outro. Merleau-Ponty defende justamente a impossibilidade de uma redução completa. Para ele, no encontro com o outro, ao tentar compreender a sua experiência, a sua visão, o sentido que esse outro dá as coisas, é impossível a suspensão completa de si para o alcance do outro (Macêdo, 2015).

Isso se dá pelo fato de serem sujeitos sociais e estarem existindo no mundo da vida (Lebenswelt). Numa pesquisa, por exemplo, pesquisador e pesquisado interagem entre si, estão envolvidos no mundo, o que para uma pesquisa fenomenológica é bastante positivo, porque, para 
compreender a experiência do outro, é importante estar implicado com esse outro com o qual se interage (Ashworth,1996, citado por Macêdo, 2015). É a impossibilidade de uma redução total que Merleau-Ponty chama de epokhēé incompleta. Merleau-Ponty também se refere a corporeidade e intercorporeidade, fazendo uso do conceito de consciência perceptiva, que seria uma consciência aberta ao mundo. Ele acredita numa consciência situada no corpo e este corpo no mundo. O próprio corpo no núcleo do sujeito e esse sujeito como um ser encarnado no mundo. Ele entende que a consciência, sendo compreendida como perceptiva, está inseparavelmente ligada ao corpo, em permanente diálogo com o mundo, e a relação do homem com o mundo se dá pela relação direta corpo-mundo, posto que é corpo vivido, corpo sentido, corpo no mundo.

Esta noção o permitirá avançar no entendimento da relação eu-outro, proposta a partir da experiência do corpo, pela intercorporeidade: o eu e o outro são órgãos de uma só carne. Dessa forma, "não se pode, ao tentar conhecer a experiência de outro, suspender a prioris porque se estaria ocultando o sujeito que conhece o mundo do mundo a ser conhecido, e isto é um contrassenso, porque o corpo e o mundo são a mesma textura ontológica” (Macêdo, 2015, p. 125).

Já no que diz respeito à hermenêutica filosófica de Hanz Georg-Gadamer, para esta pesquisa, faz-se necessária a compreensão de dois conceitos: a fusão de horizontes e a tradição, os dois elementos fundamentais que permitem, num diálogo, a contestação da verdade e a construção de um novo saber. Portanto, aqui compreenderemos tradição como a "tensão entre a novidade e aquilo que já se conhecia de experiências passadas" e fusão de horizontes como o "intercruzamento de diversas visões panorâmicas ou perceptivas de mundo, num movimento de diacronia e sincronia de tradições, a partir do qual os horizontes fazem conexão e os sujeitos se engajam num diálogo" (Macêdo, 2015, p.126-127). Então, só se pode falar em diálogo gadameriano quando a ampliação do conhecimento transforma o sujeito, suas atitudes, produzindo um saber mais autêntico.

Como resultado da articulação dos saberes filósofos supracitados, Macêdo (2015) propôs a Hermenêutica Colaborativa. A proposta dá ênfase à intersubjetividade (Merleau-Ponty, 1945/2006) e ao diálogo (Gadamer, 2003), resultando num método que busca promover uma ação intersubjetiva criativa de produção de sentidos, na qual os sujeitos se engajam e, encarnados que estão no mundo, compartilham experiências pela intercorporeidade, produzindo novos sentidos para suas experiências. Foi embasada na Hermenêutica Colaborativa e, por assim dizer, sendo guiada pela fenomenologia de Merleau-Ponty e a hermenêutica filosófica de Gadamer, que essa pesquisa pretendeu criar um espaço de compartilhamento e ressignificação de experiências vivenciadas pelos (as) genitores (as), aqui denominados colaboradores, tratandose, portanto, de uma pesquisa fenomenológica interventiva e colaborativa.
A pesquisa foi realizada no Centro de Referência Especializada em Assistência Social (CREAS) em Petrolina-PE. O CREAS, segundo o Portal Brasil, é responsável pelo atendimento de indivíduos ou famílias em situação de risco social ou que tiveram seus direitos violados. Conta, geralmente, com uma equipe multiprofissional composta por profissionais como: psicólogo, assistente social, advogado, educador, auxiliar de serviços gerais e coordenador. No CREAS Petrolina, o atendimento de assistência ao genitor (a), à criança, ao adolescente ou à família é feito semanalmente ou quinzenalmente, a depender do nível de gravidade de cada caso.

Vale a pena salientar que o CREAS Petrolina foi o espaço que forneceu anuência para que a pesquisa fosse realizada, devido à viabilidade de contato dos pesquisadores com o público alvo. No entanto, a pesquisa não consistiu numa atividade da instituição e, por isso, não teve participação de equipe multidisciplinar, prerrogativa das ações de uma instituição dessa ordem, embora se reconheça a importância dos resultados de um estudo como esse para possíveis reconfigurações em atividades do CREAS.

Para facilitar a abordagem e o convite para participação na pesquisa, foi preciso realizar três reuniões visando alcançar o máximo de potenciais colaboradores. Nestas reuniões foram explicitados aos genitores (as) os objetivos e procedimentos da pesquisa, realizado o convite de participação na pesquisa e acordado com os interessados o calendário dos encontros. Dos (as) genitores (as) contatados (as), cinco deles se disponibilizaram a participar do grupo, sendo dentre os cinco, um casal (homem e mulher) e mais três genitoras, todos atendendo aos seguintes critérios de inclusão: ser genitor (a) de criança vítima de violência sexual independente de quando tenha acontecido a violência; estar cadastrado e ter tido o primeiro atendimento no CREAS Petrolina; ser alfabetizado; e ter disponibilidade para participar de no mínimo $75 \%$ dos encontros. E como critério de exclusão estar realizando atividade de grupo em outro serviço psicológico (por se compreender que essa participação paralela poderia interferir nos resultados da pesquisa).

Visando uma melhor avaliação dos resultados do grupo interventivo, foi solicitado que, ao longo do período da coleta, os sujeitos não participariam de outros atendimentos psicológicos ofertados pelo CREAS, com exceção de alguma demanda emergencial. O estudo foi registrado sob CAEE 59319416.3.0000.5196 e autorizado pelo Comitê de Ética e Deontologia em Pesquisas com Seres Humanos (CEDEP/UNIVASF) pelo parecer 1.778.934. Foi conduzido concomitantemente à realização de encontros grupais e teve como facilitador o próprio autor da pesquisa. Devido à disponibilidade de tempo dos (as) genitores (as) e ao fato do período da coleta ter proximidade com as festividades e recessos de final de ano, foram realizados três encontros semanais, com duração média de uma hora e 30 minutos cada. Houve uma 
programação para cada encontro, objetivando a construção de um contexto de diálogo e confiança genuína entre os membros, para que houvesse respeito por cada descrição e história ali relatada. Utilizaram-se materiais como argila, música, recortes de revista e fotografias, considerando recursos artísticos como dispositivos clínicos para a manifestação da dimensão simbólica do sujeito, linguagem que permite transmitir sentimentos e emoções que o discurso lógico/dialético não é capaz de exprimir (Lima et al., 2013). Coube ao pesquisador promover um espaço de facilitação para o processo, sendo sua experiência o ponto crucial para compreender a experiência do outro.

No primeiro encontro, antes das atividades serem iniciadas, foram apresentados a cada colaborador, através da leitura do Termo de Consentimento Livre e Esclarecido (TCLE), os objetivos, métodos e as finalidades da pesquisa, assim como lhes foram garantidos total sigilo e preservação das suas identidades.

Finalizado isso, foi estabelecido um contrato deconvivência entre os participantes e o pesquisador. Este contrato partiu de definições básicas como: manter os encontros em sigilo, não chegar atrasado, respeitar as diferenças dos participantes, desligar o celular durante a atividade e não faltar mais de $25 \%$ dos encontros. Após o estabelecimento do contrato, foi realizada a atividade de modelagem em argila para facilitar a expressão do sentido da experiência de ser genitor (a) de criança vítima de violência sexual. No círculo hermenêutico proposto pela metodologia aqui empregada (Melo, Anjos, Lima \& Santos, 2015), a argila permite que o sujeito se implique com a experiência ali rememorada, sendo um recurso expressivo para a exploração do sentido dessa experiência, que, ao ser compartilhada em contexto de diálogo, facilita-se sua ressignificação pelos envolvidos no processo.

No segundo encontro, foi realizada uma dinâmica de grupo com o uso de fotos antigas (infância ou adolescência), solicitadas aos colaboradores no final do primeiro encontro. Esta dinâmica teve como objetivo favorecer o resgate da consciência histórica, permitindo a apropriação subjetiva de características pessoais passadas que pudessem viabilizar o enfrentamento da realidade da violência sexual sofrida pelos filhos. Cada colaborador apresentava sua foto, explicando o contexto da escolha, sendo posteriormente levado a refletir sobre características pessoais passadas que poderiam ajudar no enfrentamento das adversidades presentes.

No terceiro e último encontro todos estavam envolvidos na elaboração do que Ayres (2005) denomina de projeto de felicidade humana, visando a construção de estratégias para enfrentamento da situação de violência vivida pela família. Importante ressaltar que esta perspectiva concebe a felicidade não como um bem concreto, mas uma disponibilidade para projetos existenciais que favoreçam a superação de momentos limitantes na vida do sujeito. Essa atividade foi desenvolvida utilizando recortes de revistas como material para a construção dos projetos. Entendeu-se que todas as estratégias pensadas e construídas estavam na dependência do processo vivido pelos colaboradores no grupo.

É importante ressaltar que em todos os encontros, antes de iniciada a atividade do dia, era realizada uma dinâmica quebra-gelo tendo como foco o relaxamento corporal através da respiração e como principal instrumento a música. Além disso, não houve falta nos encontros por parte de nenhum (a) dos (as) genitores (as), o que contribuiu na vivência ter sido realmente um processo coletivo.

A coleta de dados se deu pela escrita de Versões de Sentido (VS), instrumento proposto por Amatuzzi (1996) e que tem sido utilizado por diversos pesquisadores desde sua criação (a exemplo de Macêdo, 2000 e Boris, 2008). Esses autores entendem que a VS, ao ser lida num encontro, favorece a versação e conversação sobre o sentido de uma experiência imediatamente após ela ter sido vivida, até que se chegue à explicitação compartilhada dos significados vividos.

Segundo Amatuzzi (2008), a VS é:

um relato livre que não tem pretensão de ser um registro objetivo do que aconteceu, mas sim de ser uma reação viva a isso, escrita ou falada imediatamente após o ocorrido, e como uma palavra primeira. Consiste numa fala expressiva da experiência imediata de seu autor, face a um encontro recémterminado. (p. 76)

Foi solicitado aos (às) genitores (as) participantes da pesquisa que produzissem uma VS ao final de cada encontro e que as lessem no encontro posterior ao de sua escrita, sendo esse diálogo a base para se compartilhar os sentidos da experiência do encontro anterior no encontro posterior. Após o primeiro encontro, o tempo dos demais foi dividido em parte para a leitura e exploração da VS; parte para novas atividades; e, nos cinco minutos finais, foi solicitada a escrita da próxima VS, que foi lida no encontro posterior e assim sucessivamente. No último encontro, foi solicitada a escrita da VS nos últimos 30 minutos, para que a última VS pudesse ser escrita e (con)versada no mesmo dia, já que não haveria mais encontros.

Ao final da pesquisa, todas as VS's foram analisadas pela equipe (pesquisador e orientadora) no intuito de compreender se os colaboradores revelaram, através da escrita, os sentidos de suas experiências, o processo vivido ao longo dos encontros, as mudanças nos modos de subjetivação (sentir, pensar e agir) durante o processo e a construção conjunta de estratégias de enfrentamento da realidade.

As Versões de Sentido foram analisadas fenomenologicamente a partir dos seguintes passos (Amatuzzi, 2008, 2009; Macêdo, 2000, 2015):

a. Leitura integral/contato com o todo: foram realizadas as leituras no encontro posterior ao da escrita da VS, do conteúdo da mesma 
por cada autor, quantas vezes fossem necessárias, para que os membros do grupo alcançassem os significados da experiência.

b. Encontro com os significados: exploração dos significados a partir de um diálogo em que todos os sujeitos envolvidos no encontro puderam se colocar/compreender/ interpretar, estando as possibilidades dos significados da experiência sujeitas à confirmação do autor da VS.

c. Presentificação do sentido da VS: o pesquisador juntamente com os colaboradores, procuraram entrar em consenso sobre o sentido de cada VS, que apenas era validado pelo autor que a escreveu.

d. Síntese do processo individual: com a finalização de todos os encontros, a equipe de pesquisa sintetizou o processo vivido por cada colaborador e o convidou a participar da análise, confirmando, propondo alterações ou mesmo negando a análise realizada.

e. Síntese do processo grupal: após a síntese do processo individual de cada colaborador, a equipe de pesquisa compreendeu o que de comum houve para os(as) genitores(as), tentando generalizar o processo vivido.

Como a pesquisa fenomenológica se faz ao caminhar, durante o processo de coleta e análise de dados, foi percebida a necessidade de analisar, também, como dados da pesquisa, as VS's e anotações produzidas pelo pesquisador no final de cada encontro realizado, visto que os conteúdos de suas VS's e a percepção sobre elas poderiam contribuir de forma significativa na clarificação dos resultados encontrados. Dessa forma, para além de trazer o que foi compreendido das VS's dos colaboradores, foi articulado a isto o sentido produzido pelo próprio pesquisador durante os encontros. Outra peculiaridade do processo diz respeito a uma colaboradora que produziu suas VS's através de desenhos, o que apesar de destoar do movimento do grupo, não impossibilitou a expressão do sentido da sua experiência, visto que os significados presentes na produção foram esgotados durante os encontros.

\section{Resultados e Discussão}

Tendo sido concluídas as análises dos dados e entendendo que esses resultados falam de um processo de transformação e mudança, foram escolhidos para os colaboradores da pesquisa nomes fictícios que fazem referência a espécies de borboletas, na tentativa de preservar suas identidades e simbolizar o processo vivenciado por eles, que os mesmos nomearam de renovação. No entanto, o pesquisador percebeu que o processo de renovação foi transforma(dor), visto que saíram do "casulo" (lugar de sofrimento) e se perceberam como seres de outras possibilidades, como liberta(dores), em busca do novo sobre eles mesmos.
Os pseudônimos escolhidos, portanto, foram retirados das espécies Agrias Claudia Claudina, Caligo Beltrão, Colobura Dirce, Eudeides Isabella Dianasa e Hleiconius Sara Apseudes, contidas no site Tudo sobre borboletas (2016). Vale salientar que a análise final realizada pela equipe de pesquisa foi validada em uma entrevista devolutiva com os colaboradores, sem que houvesse nenhuma sugestão de mudança.

No primeiro encontro, através da análise das anotações do pesquisador, foi possível compreender quais os principais fatores que influenciaram no sofrimento sentido por eles. Segundo os genitores (as), o abuso é como um marco na vida da família, que, após o episódio de violência, a tristeza é um sentimento que se faz presente no cotidiano e que mesmo tentando não se consegue esquecer. Afirmaram também que se sentem impotentes diante do tempo de espera e do perigo a que acabam sendo expostos a partir do momento em que fazem a denúncia do abuso e o agressor continua em liberdade. Afirmaram que a lentidão dos processos jurídicos gera muito sofrimento. Segundo eles, é preciso ter muita coragem para não desistir durante o caminho, e por isso entendem os pais que abandonam a luta por não aguentarem o sofrimento da espera.

Esse sofrimento relacionado à lentidão do processo revela dois fatores preocupantes. Um diz respeito ao aumento da situação de vulnerabilidade enfrentada pela família graças à lentidão do sistema jurídico; o outro é o fato de os genitores (as) acabarem associando a resolução do problema à responsabilização do agressor, o que denuncia uma visão bastante restrita da problemática. Lembrase aqui Silva, Ferriani e Silva (2012), autores que fazem refletir como é extremamente preocupante entender a resolubilidade da violência sexual apenas relacionada com a responsabilização do agressor.

Já no que diz respeito às VS's dos colaboradores, houve algo inusitado. No final de cada encontro, quando eles tinham a tarefa de escrever o material sobre o que haviam vivenciado naquele momento, revelaram que ter um(a) filho(a) abusado(a) sexualmente é uma experiência carregada de dor e sofrimento, entretanto as VS's retrataram mais o quanto o encontro foi significativo do que a condição de genitor propriamente dito. $\mathrm{O}$ investimento na escrita acabou sendo para falar sobre os benefícios de terem participado do encontro, e quando falavam sobre si, faziam isso para além do papel de ser pai ou mãe da vítima de violência sexual. Vejam-se, como exemplo, os seguintes registros: "Esse encontro foi muito gratificante pois me deu a oportunidade de expor minhas experiências, dificuldades e sofrimentos." (Beltrão) e "Esse encontro foi muito importante pois conheci pessoas diferentes, estórias de vidas diferentes e quase iguais à minha; está sendo muito bom participar desse grupo.” (Isabella)

É possível, portanto, correlacionar com a literatura quando Costa et al. (2007) referem o quanto os genitores (as) sofrem com a repetição da história do abuso. Pareceu que, ao chegarem no 
grupo e terem a oportunidade de serem cuidados, eles acabaram se afastando do lugar de genitores (as) e começaram a cuidar de si como pessoas, para além dos filhos ou da família. O movimento de foco no próprio processo pareceu estar associado à exaustão que envolveu tratar do assunto abuso sexual.

Como o segundo encontro teve o objetivo de favorecer o resgate da consciência histórica, foi possível perceber a partir das VS's resultados que se referiam às mudanças nos modos de subjetivação (sentir, pensar e agir) e às estratégias de enfrentamento desenvolvidas no processo. Ficou claro que o resgate de vivências passadas acabou enriquecendo o enfrentamento dos dias atuais, tal como propõem as últimas produções científicas da autora da Hermenêutica Colaborativa e sua equipe de pesquisa (a exemplo do proposto por Souza, Lima \& Macêdo, 2017), e isto se deu porque muitas características dos colaboradores que seriam importantes para o enfrentamento do sofrimento ou das dificuldades atuais, acabaram sendo perdidas com o passar do tempo e, através da atividade proposta no grupo, foi possível fazer esse resgate.

Sobre isso, é preciso entender que, como já defendido por Paula (2011), o abuso é como uma ruptura, um evento traumático que talvez impossibilitasse os genitores (as) darem continuidade aos projetos de vida; um marco na vida dos colaboradores, de uma forma que pôde tê-los paralisado no acontecido, o que acabou dificultando vislumbrar novas perspectivas de vida e de futuro. Dessa forma, ao chegarem no grupo, eles estavam focados no lugar de sofrimento e na experiência traumática vivenciada e, nesse processo de resgate, puderam olhar para si, buscando outras alternativas para o presente e se conectando com quem eles são através de quem eles foram no passado. Então, esse processo de olhar para o passado pareceu representar tanto uma mudança de posicionamento quanto uma forma de fortalecimento diante da situação de violência enfrentada. Como mostram os exemplos de fala a seguir:

Podemos perceber nesse encontro o quanto fomos felizes e nem sempre percebemos, porque antes não dávamos muito valor às pequenas coisas, mas são coisas muito importantes que fazem a gente feliz. Saudade dos tempos de jogar bola com os amigos e conversar. (Beltrão)

Falar do passado foi muito bom, porque relembrei de muita coisa boa que hoje não vivemos mais. Como sempre fui guerreira, trabalhei muito cedo, mas agradeço a Deus e a meus pais por ter me incentivado a trabalhar, porque hoje, enfrento tudo e não tenho medo de enfrentar a vida hoje. (Claudia)

No que diz respeito ao compartilhamento de experiências, os colaboradores revelaram que esse partilhar de histórias promoveu a diminuição da dor. Segundo eles, a partir da troca de experiências, foi possível fazer relações entre a sua história e a história do outro, elencando diferenças e semelhanças, e isso fez com que eles pudessem conhecer outras formas de lidar com as dificuldades e construir, através do diálogo, novas maneiras de enxergar os fatos, o que certifica a operacionalidade do método da hermenêutica colaborativa de Macêdo (2015) como um dispositivo de construção conjunta e produção intersubjetiva de sentido. Como exemplo disto, podemos lembrar Isabela, ao afirmar: "Esse encontro foi muito importante pois conheci pessoas diferentes, estórias de vidas diferentes e quase iguais a minha, está sendo muito bom participar desse grupo."

Apresentando resultados mais recentes da operacionalidade prática da hermenêutica colaborativa, estudos propõem que intervenções com o uso do método permitem o alívio do sofrimento quando os colaboradores de uma pesquisa compartilham experiências, além de enfatizarem que conhecer a experiência do outro por si só favorece a ressignificação da própria experiência do sofrimento (Melo et al., 2015; Souza et al., 2017). Portanto, os resultados da presente pesquisa também levam a refletir como a percepção do sofrimento alheio e a abertura conjunta para compartilhar o sofrimento são favorecedores da ressignificação da experiência e produção de novos sentidos.

Ainda relacionado com o compartilhamento de experiências, para os colaboradores, a oportunidade de conhecer novas pessoas, construir novos vínculos e fazer novos amigos é vista como uma forma de enfrentamento do sofrimento, isto porque se sentem mais fortalecidos por fazerem parte de uma rede de apoio. Como dito por Costa et al. (2007), após o abuso, é bastante comum que a família da criança acabe entrando em um ciclo de isolamento social por conta de todo julgamento moral a que acaba sendo exposta. Por esse motivo, estar em um grupo de pessoas que compreendem o seu sofrimento e construir, a partir da troca de experiências, vínculos sociais, parece ter sido um ganho muito significativo para os colaboradores. Sobre isso, Dirce, uma colaboradora, afirma: "Foi bom, encontrei uma nova amiga e falei o que estava sentindo."

Outro resultado encontrado diz respeito à escuta e à expressão. Para eles, o exercício de ter sido escutado e a oportunidade de expressar os sentimentos contribuíram no processo de melhora. Segundo as anotações do pesquisador, os colaboradores afirmaram que não costumavam dispor de um espaço onde podiam expressar a dor, o sofrimento, os desejos e os projetos, e por isso parece ter sido muito significativo usufruir de um dispositivo que possibilitasse isto, principalmente por compartilhar desse lugar com outros (as) genitores (as) que compreendiam a dor sentida. Eles começaram a perceber que, a partir da expressão de seus sentimentos, o sofrimento vivido podia florescer em novas perspectivas e vivências. Como é possível perceber na VS de Dirce: "Hoje foi bom porque consegui falar o que estava sentindo." 
E no desenho de Sara:

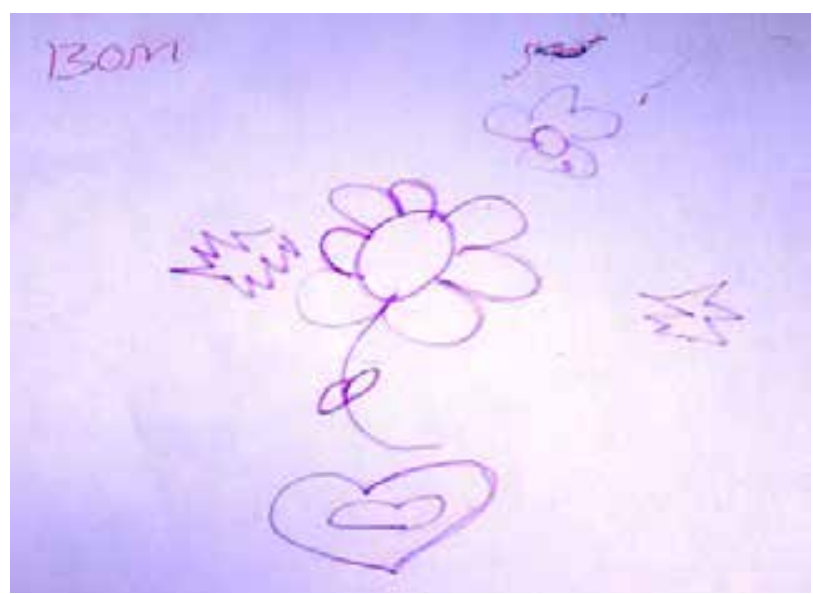

Figura 1. Coração que floresce.

Nessa VS (produzida no segundo encontro), o desenho foi interpretado no terceiro encontro como um coração que chega no grupo cheio de dor e sofrimento, entretanto começou a florescer em novas perspectivas. Aqui, é possível argumentar que uma produção artística, como dispositivo de expressão subjetiva e via de acesso à subjetividade favoreceria, em um dizer merleau-pontyano (Silva, 1994), o pensamento sensível, pois que também é linguagem falante. As VS's de Sara estiveram carregadas de sentido, e a colaboradora, em sua mudez de escrita, não deixou de revelar o sentido de sua experiência com uma riqueza de detalhes que algumas VS's escritas não conseguiam revelar.

A partir das anotações do pesquisador e da análise das VS's do terceiro encontro, foi possível destacar dois sentidos em comum entre os colaboradores: o planejamento dos projetos futuros e o sentimento de renovação. Os colaboradores afirmaram que desenvolver projetos familiares é uma forma de melhorar a qualidade de vida, visto que pensar no futuro é uma oportunidade de refletir sobre o momento atual sem necessariamente estar preso a ele. Percebeu-se que o mesmo paradigma que envolve o resgate do passado se faz presente na projeção do futuro. Ao chegarem no primeiro encontro, os colaboradores demonstraram uma certa estagnação de vida no acontecimento do abuso, o que os impossibilitava de vislumbrar outros lugares. Ao serem convocados a projetarem no último encontro o que estaria por vir, eles repensaram sobre esse lugar de sofrimento: "O encontro de hoje me fez pensar nos projetos familiares, o que podemos fazer para melhorar nossa qualidade de vida." (Beltrão). E Claudia também afirma que:

Quando cheguei no segundo encontro foi surpreendente na forma que as coisas foram sendo conduzidas, coisas que não tinha nada a ver com o decorrer da situação, fazia todo sentido. Que falar de hoje, foi maravilhoso. Porque falar de você mesmo é difícil olhar para dentro de você e poder falar de você. E falar do futuro é poder viver mais o presente. (Claudia)
Com a finalização do processo, os colaboradores revelaram o sentimento de renovação diante da experiência vivenciada, comunicando isto apesar da dor e do sofrimento ainda serem presentes. Eles registraram, através da escrita das VS's, que a vivência dos três encontros possibilitou cuidar do sofrimento e levar os dias de uma forma mais saudável, mesmo não esquecendo a causa da dor. São exemplos disso a colaboradora Dirce: "Para mim foi bom. Renovada." e Sara na VS produzida através do desenho:

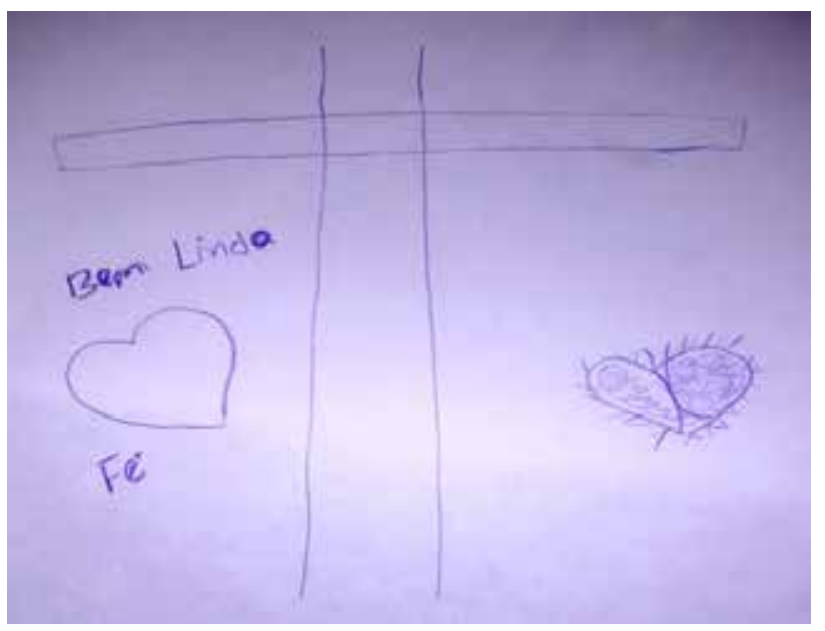

Figura 2. Mudança.

Na VS desenhada parece que a finalização do processo no grupo permitiu uma mudança em modos de subjetivação da colaboradora. Um coração que chega machucado e outro que sai mais leve. A religião, representada pela cruz, é outro instrumento de enfrentamento da violência.

Interessante perceber que esse desenho talvez represente o processo vivido por todos os colaboradores, porque o estudo possibilitou uma experiência de autocuidado que convocou os participantes a olharem para o seu próprio caminhar. Eles foram convidados a repensar sobre quem são em meio a uma rotina repleta de distrações. Utilizaram cada encontro como um degrau no processo de aproximação das suas singularidades e investiram nas suas próprias escolhas e desejos, que por tantas vezes foram colocados em segundo plano em nome da família e das responsabilidades. Foi visível o quanto eles estiveram envolvidos com a experiência e, mesmo sabendo quando seria o fim daquele trajeto no grupo, em nenhum momento deixaram de aproveitar o caminho.

\section{Conclusão}

Tendo sido alcançados os objetivos propostos, os resultados dessa pesquisa reafirmam que grupos interventivos para genitores (as) de crianças vítimas de violência sexual se configuram como uma prática de cuidado e atenção a esse público. Por este motivo, é importante que haja investimento na construção desses espaços com a clareza de que, a partir disso, as instituiçôes estarão 
prestando assistência não somente aos genitores (as), mas também aos seus filhos, entendendo que a proteção e educação das crianças são perpassadas pelo processo pessoal dos pais e mães. No entanto, reconhece-se a necessidade de compreender a singularidade de cada processo vivenciado.

É importante destacar que o instrumento de coleta de dados (VS), apesar de ter possibilitado o acesso às experiências dos colaboradores, limitou, em certa medida, a profundidade do registro do que foi vivenciado nos três encontros, visto que muito do que foi dito e experienciado não se fez presente nas produções escritas ou desenhadas. No que diz respeito às VS's desenhadas, faz-se necessário uma reflexão sobre a ampliação das suas possibilidades de produção (que até o momento se restringia a um relato escrito), já que, através de desenhos, também foi possível a uma colaboradora expressar o sentido de sua experiência.

Por esses motivos, sugerem-se novos estudos com o uso da VS a partir de outros tipos de registros linguísticos; assim também que sejam desenvolvidas pesquisas tendo como instrumento de coleta de dados, para além da VS, a gravação em áudio dos encontros e o uso de diário de bordo, objetivando registros mais completos das vivências. Acredita-se que o aumento do número de colaboradores e de encontros, bem como a possibilidade de desenvolver o estudo em outras localidades, possa contribuir para o enriquecimento da produção científica na área.

Entretanto, apesar das limitações, foi possível compreender que a metodologia utilizada, a hermenêutica-colaborativa, possibilitou muitos ganhos aos participantes do grupo. A operacionalidade prática dos encontros foi absorvida pelos colaboradores como uma estratégia de autocuidado, visto que compartilhar experiências, falar sobre o sofrimento e construir vínculos no grupo foram tidas como formas de enfrentar e minimizar a dor.

Para os pesquisadores foi bastante gratificante perceber o alcance dos objetivos da pesquisa e ver o quanto o processo de renovação e transformação também esteve relacionado ao seu próprio caminhar. A interseção entre cuidar da dor do outro e ao mesmo tempo pesquisá-la, foi uma experiência que contribuiu no desenvolvimento de uma escuta mais sensível e uma postura profissional mais empírica na vivência enquanto estagiário de Psicologia. Somado a isso, a finalização do estudo possibilitou aos pesquisadores uma entrada mais segura no mercado de trabalho no que concerne à demanda da violência sexual, a escuta psicológica e o acolhimento de famílias nos serviços de assistência social.

Espera-se, dessa forma, que este estudo contribua na sensibilização das instituições de acolhimento desse público, assim como dos profissionais de Psicologia que venham a atender essa demanda, no intuito de construir um olhar e uma escuta mais sensíveis à delicadeza e complexidade que envolve o fenômeno estudado.

\section{Referências}

Amatuzzi, M. M. (1996). O uso da versão de sentido na formação e pesquisa em psicologia. Campinas, SP: Alínea.

Amatuzzi, M.M. (2008). Por uma psicologia humana. Campinas, SP: Alínea.

Amatuzzi, M.M. (2009). Psicologia fenomenológica: uma aproximação teórica humanista. Estudos de Psicologia, Campinas, 26 (1), 93-100.

Ayres, J.R.C.M. (2005). Hermenêutica e humanização das práticas de saúde. Ciência \& Saúde Coletiva, 10 (3), 549-560.

Azevedo, M.A. (1997). Infância e violência doméstica: fronteiras do conhecimento. São Paulo: Cortez.

Boris, G.D.J.B. (2008). Versão de Sentido: um instrumento fenomenológico-existencial para a supervisão de terapeutas iniciantes. Psicologia Clínica, Rio de Janeiro, 20 (1), 165-180.

Conselho Federal de Psicologia (2009). Serviço de Proteção Social a Crianças e Adolescentes Vítimas de Violência, Abuso e Exploração Sexual e suas Famílias: referências para atuação do psicólogo. $\left(1^{\circ} \mathrm{ed}\right)$. Brasília. Recuperado em 28 de outubro, 2017, de http://site.cfp.org.br/wp-content/uploads/2009/10/ CREPOP Servico Exploracao Sexual.pdf

Costa, L. F., Penso, M. A., Rufini, B. R., Mendes, J. A. A., \& Borba, N. F. (2007). Família e abuso sexual: silêncio e sofrimento entre a denúncia e a intervenção terapêutica. Arquivos Brasileiros de Psicologia, 59(2), 245-255. Recuperado em 24 de julho, 2016, de http:// pepsic.bvsalud.org/scielo.php?script $=$ sci arttext\&pid =S1809-52672007000200013\&lng $=$ pt\&tlng $=$ pt.

Garnica, A.V.M. (1997). Algumas notas sobre pesquisa qualitativa e fenomenologia. Interface - comunicação, saúde, educação, 1(1), 109-122. Recuperado em 24 de julho, 2016, de http://www.scielo.br/pdf/ icse/v1n1/08.pdf

Habigzang, L.F., Ramos, M. S., \& Koller, S. H. (2011). A revelação de abuso sexual: As medidas pela Rede de apoio. Psicologia: Teoria e Pesquisa. 27(4), 467-473. Recuperado em 23 de julho, 2016, de http://www. scielo.br/pdf/ptp/v27n4/10.pdf

Lima, J.A., \& Alberto, M. F. P. (2010). As vivências maternas diante do abuso sexual intrafamiliar. Estudos de psicologia, 15(2), 129-136. Recuperado em 23 de julho, 2016, de http://www.scielo.br/pdf/epsic/ v15n2/01.pdf.

Lima, M.C.P., Martins, K.P.H., Rocha, L.P., Parente Jr, P.A., Castro, I.P., Pinheiro, N.M., Domingues, M. (2013). Arte e mediação terapêutica: sobre um dispositivo com adolescentes na clínica-escola. Revista Mal-Estar e Subjetividade, 13(3-4): 775-796.

Macêdo, S. M. (2000). Psicologia clínica e aprendizagem significativa: relatando uma pesquisa fenomenológica colaborativa. Psicologia em Estudo, 3 (2), 49-76. 
Macêdo, S. V. M. (2015). Clínica Humanista-Fenomenológica do Trabalho. A Construção de uma Ação Diferenciada Diante do Sofrimento no e por Causa do Trabalho. Curitiba, SP: Juruá Editora.

Melo, S.M.V., Anjos, T.S.M., Lima, A.R.O., Santos, B.L.S. (2015). A clínica humanista-fenomenológica do trabalho num contexto de supervisão de estágio profissionalizante em psicologia na Universidade Federal do Vale do São Francisco. $9^{\circ}$ Congresso Norte-Nordeste de Psicologia (p. 740). Salvador.

Merleau-Ponty, M. (1945). Fenomenologia da Percepção. São Paulo: Martins Fontes.

Paula, E. S. (2011) O abuso sexual na família: um estudo sobre o enfrentamento a partir de intervenção institucional. (Dissertação Pós-graduação em Ciências Sociais). Faculdade de Filosofia e Ciências Humanas, Salvador.

Portal Brasil. (2011). CIDADANIA E JUSTIÇA: centro de referência especializado de assistência social (CREAS). Recuperado em 23 de julho, 2016, de http://www.brasil.gov.br/cidadania-e-justica/2011/10/centro-de-referencia-especializado-de-assistencia-social-creas.

Secretaria Especial De Direitos Humanos Ministério Da Justiça E Cidadania (2015). Disque 100: Quatro mil denúncias de violência sexual contra crianças e adolescentes foram registradas no primeiro trimestre de 2015. Recuperado em 17 de julho, 2016, de http://www.sdh.gov.br.

Silva, P.M.L., Ferriani, C.G.M., \& Silva, I.A.M. (2012). Violência sexual intrafamiliar contra crianças e adolescentes: entre a prevenção do crime e do dano. Rev. Saúde Mater.Infant. 12(4). Recuperado em 28 de outubro, 2017, de www.producao.usp.br/bitstream/ handle/BDPI/40076/S1519-38292012000400007. pdf?sequence $=1$

Silva, U.R. (1994). A linguagem muda e o pensamento falante. Porto Alegre: Edipucrs.

Souza, G.W., Lima, M.B., Macêdo, S.M.V. (2017). Oficina de desenvolvimento da escuta: prática de capacitação e cuidado ao estagiário de psicologia. III Congresso Luso-Brasileiro de práticas clínicas fenomenológicas-existenciais e IX Congresso Latino-Americano de Psicologia Fenomenológica Existencial. Resgatando o caráter sensível da existência (p. 295). Rio de Janeiro.

Spíndola T. (1997) A fenomenologia e a enfermagem: algumas reflexões. Rev. Esc. Enf. USP, 31 (3), 403-9. Recuperado em 24 de julho, 2016, de http://www. ee.usp.br/reeusp/upload/pdf/387.pdf

Tudo sobre borboletas. (2016) Tudo sobre borboletas do brasil. Recuperado em 5 de abril, 2017, de http:// www.borboleta.org/2011/02/tudo-sobre-borboletas-brasileiras.html.

Waiselfisz, J. J. (2012). Mapa da Violência 2011. Os jovens do Brasil. Recuperado em 17 de julho, 2016, de http://www.mapadaviolencia.org.br/mapa2012 crianca.php.
Zambon, M. P., Jacintho, A. C. A., Medeiros, M. M., Guglielminetti, R., Marmo, D. B. (2012). Violência doméstica contra crianças e adolescentes: um desafio. Rev Assoc Med Bras , 58(4), 465-471.

Gledson Wilber de Souza é Graduado no Curso de Psicologia pela Universidade Federal do Vale do São Francisco. E-mail: gledson_wilber@hotmail.com.

Shirley Macêdo é Professora do Colegiado de Psicologia, do Programa de Pós-Graduação Interdisciplinar em Dinâmicas de Desenvolvimento do Semi-Árido (PPGDiDes) e da Residência Multiprofissional em Saúde Mental da Fundação Universidade Federal do Vale do São Francisco (UNIVASF). É Doutora em Psicologia Clínica pela Universidade Católica de Pernambuco; Mestre em Psicologia Clínica pela Pontifícia Universidade Católica de Campinas, SP Especialista em Psicologia Clínica pela Universidade Católica de Pernambuco; Graduada e Bacharel em Psicologia pela Universidade Federal de Pernambuco; e Bacharel em Administração pela Faculdade de Ciências Humanas ESUDA. E-mail: mvm.shirley@gmail.com.

Recebido em 27.06.2017

Primeira Decisão Editorial em 11.10.2017

Aceito em 27.11.2017 